University of Nebraska - Lincoln

DigitalCommons@University of Nebraska - Lincoln

2008

\title{
Blood culture and stimulation conditions for the diagnosis of tuberculosis in cervids by the Cervigam assay
}

W. R. Waters

M. V. Palmer

USDA, Mitchell.Palmer@ars.usda.gov

T. C. Thacker

K. Orloski

P. Nol

See next page for additional authors

Follow this and additional works at: https://digitalcommons.unl.edu/michbovinetb

Part of the Veterinary Medicine Commons

Waters, W. R.; Palmer, M. V.; Thacker, T. C.; Orloski, K.; Nol, P.; Harrington, N. P.; Olsen, S. C.; and Nonnecke, B. J., "Blood culture and stimulation conditions for the diagnosis of tuberculosis in cervids by the Cervigam assay" (2008). Michigan Bovine Tuberculosis Bibliography and Database. 82. https://digitalcommons.unl.edu/michbovinetb/82

This Article is brought to you for free and open access by the Wildlife Disease and Zoonotics at DigitalCommons@University of Nebraska - Lincoln. It has been accepted for inclusion in Michigan Bovine Tuberculosis Bibliography and Database by an authorized administrator of DigitalCommons@University of Nebraska Lincoln. 


\section{Authors}

W. R. Waters, M. V. Palmer, T. C. Thacker, K. Orloski, P. Nol, N. P. Harrington, S. C. Olsen, and B. J. Nonnecke 


\title{
Blood culture and stimulation conditions for the diagnosis of tuberculosis in cervids by the Cervigam assay
}

\author{
W. R. Waters, M. V. Palmer, T. C. Thacker, K. Orloski, P. Nol, N. P. Harrington, \\ S. C. Olsen, B. J. NONNECKE
}

\begin{abstract}
Mitogen- and antigen-induced interferon- $\gamma($ IFN- $\gamma$ ) responses of peripheral blood leucocytes from cervids were evaluated by a commercial whole-blood assay. The assay was applied to Mycobacterium bovis-infected white-tailed deer and reindeer, $M$ bovis BCG-vaccinated white-tailed deer and elk, and unvaccinated, uninfected white-tailed deer, fallow deer, elk and reindeer. The responses of the $M$ bovis-infected white-tailed deer to pokeweed mitogen (PWM) varied with time and between individuals. The responses of the $M$ bovis-infected reindeer to PWM and $M$ bovis purified protein derivative (PPD) were positively associated. Samples from tuberculosis-free captive herds in various parts of the USA were also evaluated. Four per cent of fallow deer, 20 per cent of elk, 44 per cent of white-tailed deer, and 91 per cent of reindeer had responses to PWM exceeding 0.25 $\Delta$ optical density, that is, PWM stimulation minus no stimulation. The specificity of the responses to $M$ bovis PPD and a Mycobacterium tuberculosis complex-specific antigen rESAT-6:CFP-10, excluding animals not responding to PWM, ranged from 78 per cent to 100 per cent and was dependent upon the species and the positive response cut-off value. The results show that the commercial assay is valid for the detection of TB in reindeer; however, further development of the assay will be required before it is used in surveillance programmes for white-tailed deer, fallow deer, and elk.
\end{abstract}

Veterinary Record (2008) 162, 203-208

W. R. Waters, DVM, PhD, M. V. Palmer, DVM, PhD, T. C. Thacker, MS, $\mathrm{PhD}$, Tuberculosis Research Project,

S. C. Olsen, DVM, PhD, Brucellosis Research Project,

B. J. Nonnecke, MS, PhD, Periparturient Diseases of Cattle Research Project, National Animal Disease Center, Agricultural Research Service, United States Department of Agriculture (USDA), Ames, Iowa 50010, USA K. Orloski, DVM, MS, DACVPM,

National Tuberculosis Eradication Program, Veterinary Services, P. Nol, DVM, MS, National Wildlife Research Center, Animal and Plant Health Inspection Service (APHIS), USDA, Fort Collins, CO 80521, USA, N. P. Harrington, DVM, $\mathrm{PhD}$,

Ottawa Laboratory Fallowfield, Canadian Food Inspection Agency, Ottawa, Ontario, K2H 8P9 Canada
FARMED deer constitute a significant alternative livestock industry, with numbers exceeding two million in New Zealand, one million in China, 500,000 in the USA, 400,000 in Russia and 100,000 in Canada (Griffin and Mackintosh 2000). They are exposed to other livestock and to free-ranging wildlife and are moved between herds and across borders, and there is therefore a risk that infectious diseases may spread among and between farmed deer, traditional livestock and free-ranging wildlife. In addition, many deer are kept in parks reserves and private estates for hunting, zoological, and aesthetic purposes, and their intensive management promotes the spread of infectious diseases among them.

The causal agent of bovine tuberculosis (тв) is Mycobacterium bovis. This zoonotic pathogen has a wide host range and is the species of Mycobacterium species most often isolated from tuberculous cattle and captive deer. There are several wildlife maintenance hosts of bovine тв, including the Eurasian badger (Meles meles), brushtail possum (Trichosurus vulpecula), white-tailed deer (Odocoileus virginianus), bison (Bison bison), lechwe antelope (Kobus leche) and African buffalo (Syncerus caffer) (de Lisle and others 2001). In addition to white-tailed deer, $M$ bovis has been isolated from red deer (Cervus elaphus), sika deer (Cervus nippon), roe deer (Capreolus capreolus), fallow deer (Dama dama), muntjac deer (Muntiacus reevesi), mule deer (Odocoileus hemionus), and several other deer species (Griffin and Mackintosh 2000, Delahay and others 2001, 2006). Free-ranging and captive deer are implicated in the spread of $M$ bovis to cattle in the USA, Canada and New Zealand (Essey and Koller 1994, de Lisle and others 2001, O'Brien and others 2006) and to human beings (Fanning and Edwards 1991, Whiting and Tessaro 1994, Wilkins and others 2003, Bucholz 2005). The prevalence of TB in free-ranging deer populations in southwest England has been estimated to range from 1 per cent for roe and red deer to 4.4 per cent for fallow deer and $5 \cdot 2$ per cent for muntjac deer. A recent assessment determined that free-ranging deer in the UK are a potential source of infection to cattle in localised areas (Delahay and others 2006).

In the USA, the prevalence of ТВ in free-ranging white-tailed deer in certain areas of Michigan reached 5 per cent in the late 1990s, but increased hunting and limitations on wide-scale feeding practices have decreased this rate to approximately 1 per cent in these areas (O'Brien and others 2006). In western Spain, there was a steady increase in the prevalence of $M$ bovis infection in free-ranging Iberian red deer (Cervus elaphus hispanicus) between 1997 and 2002, reaching 1.7 per cent (Parra and others 2006). $M$ bovis has also been detected in captive herds of deer in the USA, Canada, New Zealand, Europe and Asia. In the USA, the spread of bovine TB in captive herds is strongly associated with inter-herd and cross-country movements of infected deer (Essey and Koller 1994). M bovis was diagnosed in 41 captive herds of deer in the USA between 1991 and 2003 (Massengill 2005), in 35 captive herds in Canada between 1989 and 1998 (Essey and Koller 1994, Massengill 2004) and in 41 of 14,842 farmed deer slaughtered in Ireland between 1993 and 1996 (Quigley and others 1997). тв has also been diagnosed in captive axis deer (Cervus axis) in India (Baska and others 1975), in elk (Cervus elaphus nelsoni) in Korea (Kim and others 2002) and sika deer in Japan (Itoh and others 1992) and China (Shilang and Shanzhi 1985).

As a result of a series of confirmed cases in the mid 1980s, TB was designated a 'notifiable' disease in farmed deer in Great Britain (R. de la Rua, personal communication). Similarly, a 1991 outbreak in captive elk, attributed to the importation of an infected elk, encouraged the government and industry leaders in the USA to draft a Uniform Methods and Rules for the Eradication of bovine Тв in captive cervids (Essey and Koller 1994). In conjunction with the Deer Farmers' Association and the Deer Branch of the New Zealand Veterinary Medical Association, the New Zealand Ministry of Agriculture and Fisheries adopted a voluntary TB control scheme in 1984 followed by a compulsory national TB control scheme in 1991 (de Lisle and others 2001). Such тв control campaigns have generally relied on test and removal, slaughterhouse surveillance, movement restrictions and/or wildlife reservoir control strategies. In the UK, USA and Canada, farmed deer are monitored by a combination of slaughter surveillance and skin-testing strategies. In the USA the programme is voluntary, but required for interstate transport and herd accreditation. In Canada, a negative TB test for each deer is required for a change of ownership or any movement, except to slaughter. In New Zealand, captive deer more than six months of age are monitored regularly by skin testing (approximately 700,000 were tested in 2004) and all deer are inspected for lesions 
at slaughter (approximately 600,000 were tested in 2004). In contrast with New Zealand, compliance with TB control strategies in many other countries is poor. In 2003, less than 6 per cent of approximately 500,000 captive deer in the USA were tested for ТВ and less than 1 per cent of 363 captive herds in the UK submitted to voluntary testing. The reasons for such poor compliance include inadequate handling facilities, injuries resulting from the handling required, the poor perception by owners of the specificity of skin testing in cervids, and in the USA, the reduction in interstate movements due to the restrictions imposed as a result of chronic wasting disease. Estimates of the sensitivity and specificity of skin tests for naturally infected red deer, fallow deer and white-tailed deer vary according to the study and species, with ranges from 80 to 84 per cent for sensitivity and 46 to 86 per cent for specificity (Palmer and others 2001); no estimates are available for naturally infected reindeer (Rangifer tarandus).

A blood-based тв test for initial surveillance might increase the compliance of deer farmers. Ancillary bloodbased tests currently used in TB control programmes around the world include the fluorescence polarisation assay, ELISA and lateral flow antibody-based tests, in addition to assays based on interferon- $\gamma$ (IFN- $\gamma$ ), for example, the Cervigam assay (Prionics) and lymphocyte blastogenesis. Their use varies between countries and they are not widely utilised with cervids. The Cervigam assay is particularly attractive owing to the widespread acceptance of other assays based on IFN- $\gamma$, for example, Bovigam (Prionics) for cattle and Quantiferon Gold (Cellestis) for human beings.

The aim of this study was to evaluate the Cervigam assay for TB surveillance by applying it to samples from four species of captive cervid of significance to the national programme in the USA. Its objectives were to evaluate a positive standard as an indicator of the performance of the assay and to determine its specificity with samples from ТВ-free herds. Antigens used for the specificity studies include $M$ bovis purified protein derivative (PPD), a complex antigen mixture and a fusion of recombinant Early Secreted Antigenic Target- $6 \mathrm{kDa}$ protein and Culture Filtrate Protein 10 (rESAT-6-CFP-10), generally a Mycobacterium tuberculosis-complex-specific antigen. Both antigens are commonly used in TB tests based on IFN- $\gamma$.

\section{MATERIALS AND METHODS}

\section{Animals, $M$ bovis infection, and $M$ bovis BCG vaccination}

Eleven yearling white-tailed deer were given 300 colony forming units (cfu) $M$ bovis strain $95-1315$ by intratonsillar instillation as described by Thacker and others (2006) and Palmer and others (2006), and 13 reindeer were given $1 x$ $10^{5} \mathrm{cfu}$ of the same strain by the same route. Blood was collected monthly during the six months after the challenge for evaluation of responses to mitogen and antigen. Infection was confirmed postmortem in each animal by pathological examination and bacteriological culture of tissues (Palmer and others 2006, Thacker and others 2006). All the inoculated reindeer were classified as reactors to a comparative cervical skin test at 90 and 240 days after inoculation (Palmer and others 2006); the white-tailed deer were not skin tested. Despite the different doses administered the distribution and severity of the lesions were similar in the white-tailed deer and reindeer.

Eight yearling white-tailed deer and four elk were vaccinated subcutaneously with $5 \times 10^{7} \mathrm{cfu} M$ bovis BCG Pasteur as described by Waters and others $(2002,2004)$. Blood was collected six weeks after the vaccination to evaluate the effects of delays in setting up the assay (to mimic overnight delivery) on the IFN- $\gamma$ responses. All the vaccinated white-tailed deer were classified as reactors to a comparative cervical skin test

\begin{tabular}{|c|c|c|c|}
\hline \multirow[b]{2}{*}{ Mitogen } & \multirow[b]{2}{*}{ Concentrations $(\mu \mathrm{g} / \mathrm{ml})$} & \multicolumn{2}{|c|}{ Mean (se) optical density } \\
\hline & & Elk & Reindeer \\
\hline \multirow[t]{3}{*}{ Pokeweed mitogen } & 20 & $0.288(0.02)^{*}$ & $1.087(0.18)^{*}$ \\
\hline & 10 & $0.275(0.02)^{*}$ & $1.041(0.17)^{*}$ \\
\hline & 5 & $0.160(0.05)$ & $0.954(0.15)^{*}$ \\
\hline \multirow[t]{3}{*}{ Concanavalin A } & 20 & $0.103(0.05)$ & $0.090(0.01)$ \\
\hline & 10 & 0.057 & $0.098(0.01)$ \\
\hline & 5 & 0.073 & $0.097(0.01)$ \\
\hline \multirow[t]{4}{*}{ Phytohaemagglutin } & 20 & $0.085(0.01)$ & $0.152(0.03)^{*}$ \\
\hline & 10 & $0.136(0.03)$ & $0.226(0.05)^{*}$ \\
\hline & 5 & $0.171(0.05)$ & $0.585(0.16)^{*}$ \\
\hline & 1 & ND & $0.137(0.01)^{*}$ \\
\hline Phosphate-buffered saline & NA & 0.059 & $0.081(0.01)$ \\
\hline
\end{tabular}

* Significantly different from phosphate-buffered saline $(\mathrm{P}<0.05)$

NA Not applicable, ND Not determined

four-and-a-half months after they were vaccinated, and all the elk reacted similarly after eight months.

For the specificity studies, that is the response of uninfected deer to $M$ bovis antigens, samples were collected from TB-monitored herds with no history of TB. Samples were obtained from fallow deer in Iowa, North Carolina and Texas, from elk in Iowa, Minnesota, North Carolina, Wisconsin and Ontario Canada, from white-tailed deer in Iowa and Wisconsin, and from reindeer in Alaska, Colorado, Iowa, Michigan, Nebraska, Ohio, North Dakota, Oregon, Pennsylvania, Tennessee and Wisconsin. The samples from Iowa were processed immediately and those from the other states within 24 hours of collection.

\section{Whole blood cultures and analysis of IFN- $\gamma$ production}

Heparinised blood was dispensed in $1.5 \mathrm{ml}$ aliquots into individual wells of a 24-well plate (Falcon 353047; Becton Dickinson). Treatments included no stimulation (phosphate-buffered saline [PBS] only), and stimulation with 20 $\mu \mathrm{g} / \mathrm{ml}$ Mycobacterium avium PPD (PPDa) (Prionics), $20 \mu \mathrm{g} / \mathrm{ml}$ $M$ bovis PPD (PPDb) (Prionics), $10 \mu \mathrm{g} / \mathrm{ml} \mathrm{rESAT-6:CFP-10,} \mathrm{or}$ mitogen (Table 1) in PBS as described by Palmer and others (2004) and Waters and others (2006). Several mitogens, including phytohaemagglutinin, concanavalin-A and poke weed mitogen (PWM) were evaluated for use as polyclonal stimulators of IFN- $\gamma$ secretion by blood leucocytes from elk and reindeer (Table 1). The mitogens were not titrated for the samples from fallow deer owing to the limited volume of blood available for testing.

As a result of this comparison, PWM at $20 \mu \mathrm{g} / \mathrm{ml}$ was selected for use in subsequent studies. Diagnostic laboratories in the USA generally consider a PWM response of either $0 \cdot 1$ or $0 \cdot 25 \Delta$ OD as indicative of a positive IFN- $\gamma$ response, that is, with Bovigam and with a limited number of samples for Cervigam.

In addition to the standard assay procedure, blood tubes were held for eight or 24 hours before culture to determine

TABLE 2: Relative specificity of the Cervigam assay for animals with positive responses to pokeweed mitogen (PWM)

\begin{tabular}{|c|c|c|c|c|c|}
\hline \multirow[b]{2}{*}{ Species* } & \multirow[b]{2}{*}{ Number } & \multicolumn{2}{|c|}{ PPDb-PPDa and PPDb-PBS } & \multicolumn{2}{|c|}{ rESAT-6:CFP-10-PBS } \\
\hline & & $<0.1(\%)$ & $<0.05(\%)$ & $<0 \cdot 1(\%)$ & $<0.05(\%)$ \\
\hline Elk & 51 & 90 & 78 & 100 & 96 \\
\hline White-tailed deer & 95 & 98 & 92 & 97 & 95 \\
\hline Reindeer & 106 & 91 & 83 & 94 & $87 \cdot 5$ \\
\hline
\end{tabular}

* Animals were from TB-monitored herds without any previous history of TB

PPDa Mycobacterium avium purified protein derivative, PPDb Mycobacterium bovis purified protein derivative 
(a)

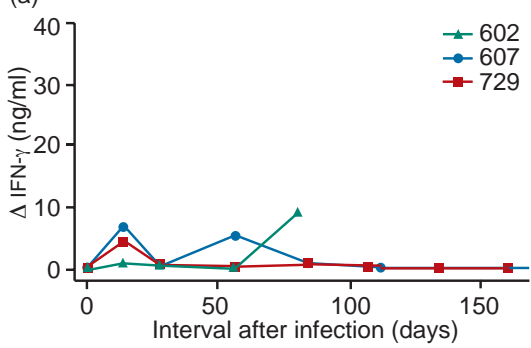

FIG 1: Variations in the capacity of blood leucocytes from 11 Mycobacterium bovis-infected white-tailed deer to respond to pokeweed mitogen (PWM). Blood was collected into heparinised tubes from infected deer at regular intervals and stimulated with $\mathbf{2 0}$ $\mu \mathrm{g} / \mathrm{ml}$ PWM or phosphate-buffered saline. After 48 hours incubation at $37^{\circ} \mathrm{C}$ in 5 per cent carbon dioxide in air, interferon- $\gamma$ (IFN- $\gamma)$ concentrations in plasma were determined by the Cervigam assay (Prionics). The deer

could be divided into (a) low, (b) moderate and (c) high responders in terms of the difference between PWM-stimulated and non-stimulated cultures ( $\Delta \mathrm{ng} / \mathrm{ml})$. The numbers refer to the individual animals

the effects of delays on the response. The blood cultures were incubated for 48 hours, and plasma was separated by centrifugation and stored at $-80^{\circ} \mathrm{C}$. The concentrations of IFN- $\gamma$ in plasma were determined with an ELISA-based kit (Cervigam; Prionics). The absorbance of the standards and test samples was read at $450 \mathrm{~nm}$ on an ELISA place reader (Molecular Devices). Individual samples were analysed in duplicate and the assay was repeated if the duplicate responses were not consistent. The concentrations of IFN- $\gamma(\mathrm{ng} / \mathrm{ml})$ in the test samples were determined by comparing the absorbance of the test samples with the absorbance of the standards within the linear response of the assay. The data are also presented as optical density (OD) readings or as differences between the response to antigen or mitogen and the response to PBS $(\Delta \mathrm{OD}$ or $\Delta$ IFN- $\gamma[\mathrm{ng} / \mathrm{ml}])$.

The interpretation of the responses to antigen was based on methods commonly used in the USA for the Bovigam assay, and a limited number of tests with the Cervigam assay. With this method, the responses to PPDb must exceed the responses to both PPDa and PBS by a given cut-off $(0 \cdot 1$ or $0 \cdot 05 \Delta$ OD) to be considered positive. The responses to the specific antigen (rESAT-6:CFP-10) were compared with the respective responses to PBS. The data are presented as the percentage of animals with responses to PPDb or rESAT-6:CFP-10 up to $0 \cdot 1$ or $0.5 \Delta$ OD (Table 2).

\section{Statistical analysis}

The data were analysed by a one-way analysis of variance followed by a Tukey-Kramer multiple comparisons test, using a commercially available statistics programme (InStat 2.00;

\begin{tabular}{|c|c|c|c|c|}
\hline Species* & Number & Mean (se) & Median (range) & $\Delta \mathrm{OD}>0.25(\%)$ \\
\hline Fallow deer & 213 & $0.085(0.02)$ & $0.035(0-3.637)$ & $4 \cdot 2$ \\
\hline Elk & 123 & $0.174(0.02)$ & $0.096(0-1.354)$ & $20 \cdot 3$ \\
\hline White-tailed deer & 171 & $0.426(0.05)$ & $0.168(0-2.862)$ & 43.9 \\
\hline Reindeer & 116 & $1.517(0.08)$ & $1.391(0 \cdot 120-3 \cdot 260)$ & 91.4 \\
\hline
\end{tabular}

* Animals were from TB-monitored herds without any previous history of TB
GraphPAD Software). Pearson's product-moment correlations were computed between the IFN $-\gamma$ concentrations in plasma stimulated with pokeweed mitogen or PPDb.

\section{RESULTS}

The magnitude of the responses to PWM was dependent upon the species of deer (Table 3). Ninety-one per cent of the reindeer had responses to PWM exceeding $0.25 \Delta \mathrm{OD}$, whereas less than 44 per cent of the other deer species had responses to PWM exceeding $0 \cdot 25 \Delta$ OD. The response by fallow deer was particularly poor with less than 5 per cent having a response to PWM exceeding $0 \cdot 25 \Delta$ OD. The percentages of PWM responses exceeding $0 \cdot 1 \Delta$ OD were 22 per cent, 46 per cent, 56 per cent and 98 per cent for the fallow deer, elk, white-tailed deer and reindeer, respectively. The mean PWM responses by the white-tailed deer and reindeer from the TBmonitored herds were similar to those observed by Palmer and others (2004) and Waters and others (2006) in M bovisinfected and control deer.

The OD readings were standardised to units of $\mathrm{ng} / \mathrm{ml}$ for longitudinal studies. The responses of the $M$ bovis-infected white-tailed deer to PWM varied widely between individual deer and over time (Fig 1). Some deer had PWM responses that never exceeded $10 \mathrm{ng} / \mathrm{ml}$ (equivalent to approximately $0 \cdot 2 \Delta \mathrm{OD}$ ) (Fig 1a) and were categorised as low responders, but other deer had responses that exceeded $30 \mathrm{ng} / \mathrm{ml}$ (equivalent to approximately $0.4 \Delta \mathrm{OD}$ ) (Fig 1c) and were categorised as high responders. Over time, the responses of individual deer to PWM ranged from 0 to $30 \mathrm{ng} / \mathrm{ml}$. Similar variations in the responses of uninfected white-tailed deer to PWM were detected (data not shown).

The responses of the $M$ bovis-infected reindeer and white-tailed deer to PWM and PPDb were positively correlated $(\mathrm{P}<0.0001)$ (Fig 2). However, the responses of the white-tailed deer were not as large, with numerous samples in the minimal response range, as indicated by the cluster in the lower left corner of Fig 2a. Thirty-five per cent of the infected white-tailed deer did not have responses to both PWM and $M$ bovis PPD exceeding $0.25 \Delta \mathrm{OD}$, indicated by the shaded box in Fig 2 a.

Under field conditions, samples are routinely shipped overnight, so that there is a delay before they are analysed. However, delays of eight or 24 hours did not significantly affect the response to PWM or PPDb of white-tailed deer or elk vaccinated with $M$ bovis BCG (Fig 3), in agreement with the results of studies with reindeer (Waters and others 2006). However, shipping by overnight courier may result in temperature fluctuations, excessive vibrations and atmospheric pressure changes. Also, caution is needed in the interpretation of these findings owing to limitations in the stimulation by PWM of samples from elk and white-tailed deer, and their modest response to vaccination. For white-tailed deer, fallow deer and reindeer, the ability to respond to PWM was not affected by overnight transport because the responses of samples processed immediately were comparable to those processed after being transported for approximately 24 hours. In contrast, 86 of the 104 samples from elk ( 83 per cent) that were shipped overnight failed to respond to PWM, compared with 12 of 19 (63 per cent) of those that were processed immediately.

Samples were obtained from TB-free herds across the USA and from Canada to evaluate the specificity of the test relative to PPDb and rESAT-6:CFP-10. Animals with PWM responses less than $0 \cdot 25 \Delta$ OD were excluded, as well as all the fallow deer because only $4 \cdot 2$ per cent of them had PWM responses exceeding $0 \cdot 25 \Delta$ OD. Table 3 shows that $20 \cdot 3$ per cent of elk, 43.9 per cent of white-tailed deer and 91.4 per cent of reindeer had responses to PWM exceeding 0.25 $\Delta$ OD. The inter- 
pretation of the responses to antigen was based on methods commonly used in the USA for the Bovigam assay, and the results of a limited number of tests with the Cervigam assay. With this method, the responses to PPDb must exceed the responses to both PPDa and PBS by a given amount, that is $0 \cdot 1$ or $0.05 \Delta \mathrm{OD}$, to be considered positive. The responses to the specific antigen rESAT-6:CFP-10 were compared to the responses to PPDb and no stimulation, that is PBS. Specificities ranged from 78 to 100 per cent depending upon the species of deer, the antigen, and the cut-off value (Table 2). In general, slightly higher specificities were obtained with rESAT-6 CFP-10 than with PPDb.

\section{DISCUSSION}

The initial development of IFN- $\gamma$-based tests for TB surveillance requires a consistent stimulant to demonstrate the functional capacity of the sample, a determination of specificity with a reasonable number of viable samples from uninfected animals, and the ability to detect responses to specific antigens by tuberculous animals. Prior studies have demonstrated the potential for IFN- $\gamma$-based tests to detect tuberculous whitetailed deer, elk and reindeer (Slobbe and others 2000, Palmer and others 2004, Harrington and others 2006, Waters and others 2006). For reindeer, these findings were extended: PWM was identified as a reliable indicator of IFN- $\gamma$ protein production, few samples were excluded owing to their inability to produce IFN- $\gamma$ in response to the positive control stimulant, and the specificity of the assay was determined to be from approximately 83 to 94 per cent depending upon the antigen and the cut-off value applied. The specificity of the assay was at least comparable to the best estimates for the range of specificities of skin testing of other cervid species, that is, 46 to 86 per cent (Palmer and others 2001). An estimate for the specificity of skin testing in reindeer is not available, but there are anecdotal reports of many false positive reactions. These findings show that the Cervigam assay is potentially useful for the surveillance.

In contrast, the findings show that the Cervigam assay in its present form is of limited usefulness with samples from white-tailed deer, elk and fallow deer. A major concern was the poor response to mitogen stimulation by more than 50 per cent of the samples from each of these species. With $M$ bovis-infected white-tailed deer, a poor response to PWM indicated a concurrent poor response to mycobacterial antigen. Only two of 63 samples from infected white-tailed deer had a response to PWM of less than $0 \cdot 25 \Delta$ OD and a concurrent response to $M$ bovis PPD of more than $0.05 \Delta$ OD, the lowest recommended cut-off for a positive response. Only 60 per cent of the samples from $M$ bovis-infected white-tailed deer showed a response to PWM exceeding $0 \cdot 25 \Delta$ OD and these responses varied widely with time and between individual deer. These findings indicate either that the sample leucocytes were unable to produce IFN- $\gamma$ consistently, or that the assay was unable to detect the cytokine consistently.

The failure of the tests my be related to the biology of the host's response, the interpretation of the assay, the failure of the assay, and/or the poor quality of the sample. Captive deer are particularly prone to acute stress when handled, which may result in sudden increases in the plasma concentration of cortisol and/or other cytokine response inhibitors (Rehbinder and others 1982, Kock and others 1987). High levels of cortisol may result in reductions in IFN- $\gamma$ due to the inhibition of transcription factor NF-kB. The mechanisms of the regulation of IFN- $\gamma$ gene expression, including positive and negative feedback loops of production, are virtually unknown for deer. Translation of the human IFN- $\gamma$ gene is inhibited by the activation of a RNA-dependent protein kinase via a pseudoknot sensor on the $5^{\prime}$-untranslated region of IFN- $\gamma$ mRNA, and the (a)

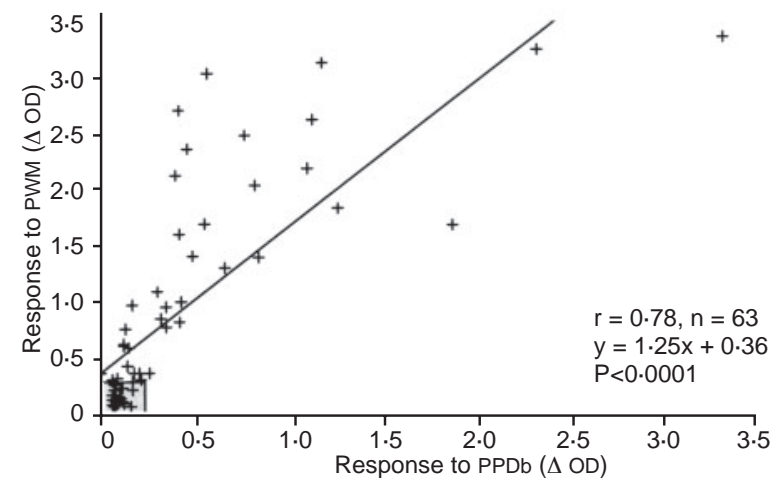

(b)

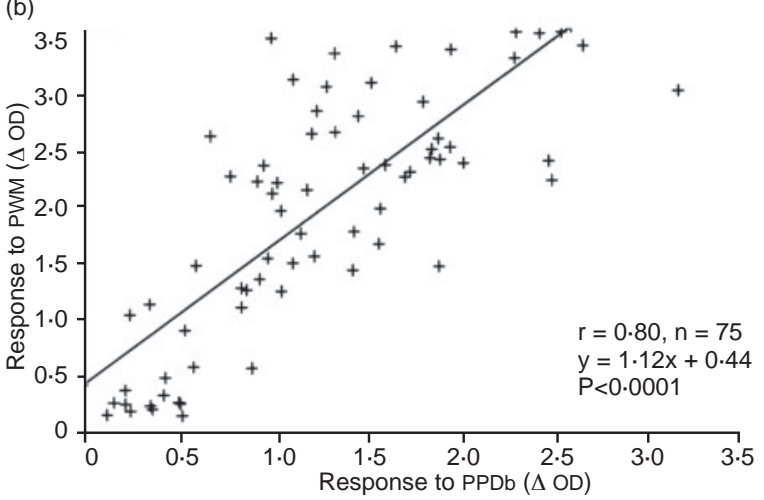

FIG 2: Correlations between the responses to pokeweed mitogen (PWM) and Mycobacterium bovis purified protein derivative (PPDb) of (a) white-tailed deer and (b) reindeer, at intervals after their intratonsillar inoculation with $\boldsymbol{M}$ bovis. Heparinised blood was stimulated with $20 \mu \mathrm{g} / \mathrm{ml}$ PWM and $M$ bovis PPD. After 48 hours incubation at $37^{\circ} \mathrm{C}$ in 5 per cent carbon dioxide in air interferon- $\gamma$ (IFN- $\gamma$ ) concentrations in plasma were determined by the Cervigam assay (Prionics). OD Optical density subsequent phosphorylation of eukaryotic initiation factor$2 \alpha$ (Kaempfer 2003). Furthermore, T cell activation may be inadequate owing to the presence of inhibitory cytokines, other inhibitory factors, or a lack of co-stimulation. Another reason for the inconsistent detection of IFN- $\gamma$ in the assay may be the degradation of synthesised IFN- $\gamma$ as a result of the activation of proteases or inhibitors of glycoprotein-processing enzymes (Kosuge and Toyoshima 2000). Alternatively, changes in the glycosylation of IFN- $\gamma$ may decrease its halflife. The inhibition of the extracellular release of synthesised IFN- $\gamma$, or the upregulation of IFN- $\gamma$ receptors with immediate binding of synthesised IFN- $\gamma$, or the masking of IFN- $\gamma$ by other factors, could also reduce the availability of free IFN- $\gamma$ in stimulated plasma.

The mitogens commonly used as positive control stimulants may not consistently induce acceptable quantities of IFN- $\gamma$ in samples from captive deer, and the interpretation of the assay is difficult without a consistent positive control stimulus. The results of this study emphasise the need for an adequate cut-off value for the assurance of quality control. A minimal cut-off value of $0 \cdot 1 \Delta \mathrm{OD}$, as used in some laboratories in the USA, is probably insufficient to assure the test's validity. The unsuccessful stimulation with mitogens may indicate either that there are different mechanisms of activation in cervids, or that there are inhibiting factors in cervid blood. The antibodies used for the Cervigam assay may not recognise IFN- $\gamma$ from different deer species (as indicated with fallow deer) and polymorphisms in antigen-binding sites may result in variability in detection between individual animals (as indicated with white-tailed deer). Delays in setting up the assay did not significantly affect the response (Fig 3), but samples from deer may be subject to interference resulting from temperature fluctuations and other transport-associated events, such as excessive vibrations and shaking. In the elk, a higher proportion of the samples that were shipped overnight failed to respond to PWM than of the samples that were processed immediately, indicating that transport may 
(a)

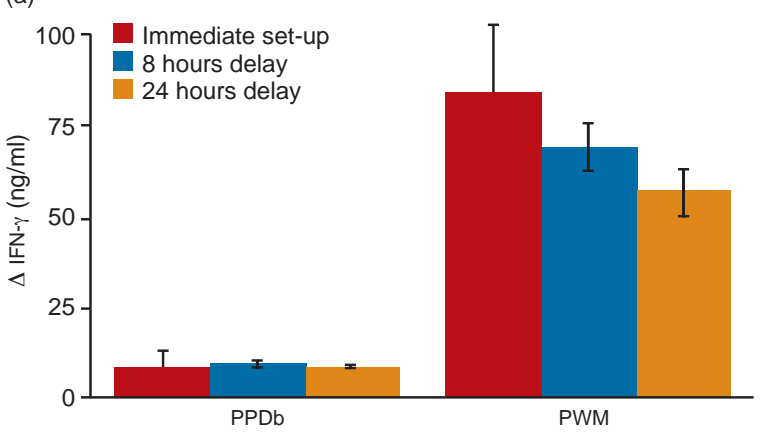

3: Effects of holding time on the mean (se) on interferon- $\gamma$ (IFN- $\gamma$ ) responses of blood samples from (a) eight white-tailed deer and (b) four elk, which had been vaccinated with Mycobacterium bovis BCG, to stimulation with pokeweed mitogen (PWM) or Mycobacterium bovis purified protein derivative (PPDb), measured with the Cervigam assay (Prionics)

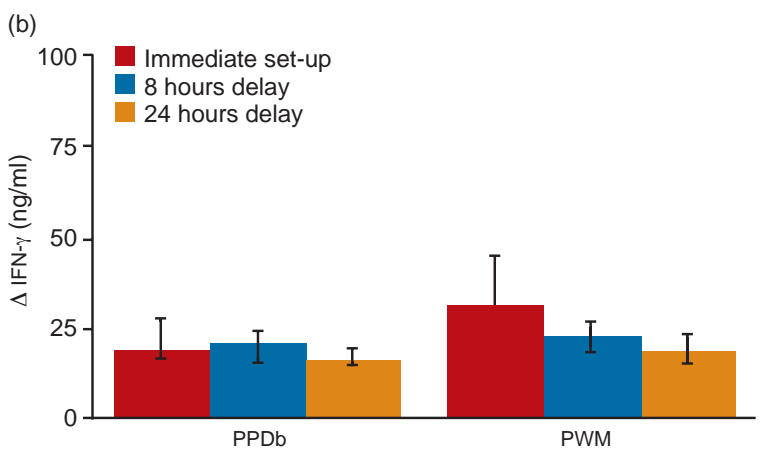

cause interference beyond any caused by delays in setting up the assay. For the further development of the test it may be necessary to evaluate additional positive control stimulants, for example, ionomycin, phorbol-12-myristate 13-acetate and recombinant interleukin-2, or cocktails of positive control stimulants, to establish IFN- $\gamma$ protein sequences from different species of deer (at present only the sequence for red deer has been published) (Sweeney and others 2001), and investigate different combinations of antibodies for the sandwich ELISA (Buchan and Griffin 1990), and/or enhanced sample delivery/stimulation procedures.

\section{ACKNOWLEDGEMENTS}

The authors thank the North American Deer Farmers' Association, the Reindeer Owners and Breeders' Association, the North American Elk Breeders' Association, as well as the numerous veterinary practitioners and captive cervid owners for providing samples for testing. Funds were provided, in part, by the USDA, APHIS for the infection and vaccination trials. Jessica Pollock, Shelly Zimmerman, Bart Olthoff, Mike Howard, Rachel Huegel and Peter Lasley provided excellent technical assistance. The authors are grateful to Dr C. Minion, Iowa State University for a supply of rESAT-6:CFP-10.

\section{References}

BASKA, D. K., CHATTERJEE, A., NEOGI, M. K. \& SAMANTA, D. P. (1975) Tuberculosis in captive deer. Indian Journal of Animal Health 14, 135-136 BUCHAN, G. S. \& GRIFFIN, J. F. (1990) Identification of heterologous monoclonal antibodies that cross-react with cervine leukocyte subpopulations. Veterinary Immunology and Immunopathology 24, 247-257

BUCHOLZ, T. J. (2005) Bovine TB strain confirmed in Michigan hunter: hunters reminded to wear gloves when cleaning game. Michigan Department of Community Health. www.michigan.gov/mdch/0,1607,7-132-8347-107460-M,00.html. Accessed February 13, 2008

DElAHAY, R. J., DE LEEUW, A. N., ClARIDGE, M., HARRIS, A., CHEESEMAN, C. L., BARLOW, A. M., MILLAR, M. F. \& CLIFTONHADLEY, R. S. (2001) First report of Mycobacterium bovis in a muntjac deer. Veterinary Record 149, 95-96

DELAHAY, R. J., SMITH, G. C., BARLOW, A. M., WALKER, N., HARRIS, A.,
CLIFTON-HADLEY, R. S. \& CHEESEMAN, C. L. (2006) Bovine tuberculosis infection in wild mammals in the south-west region of England: a survey of prevalence and a semi-quantitative assessment of the relative risks to cattle. Veterinary Journal 173, 287-301

DE LISLE, G. W., MACKINTOSH, C. G. \& BENGIS, R. G. (2001) Mycobacterium bovis in free-living and captive wildlife, including farmed deer. Revue Scientifique et Technique - Office International des Epizooties 20, 86-111

ESSEY, M. A. \& KOLLER, M. A. (1994) Status of bovine tuberculosis in North America. Veterinary Microbiology 40, 15-22

FANNING, A. \& EDWARDS, S. (1991) Mycobacterium bovis infection in human beings in contact with elk (Cervus elaphus) in Alberta, Canada. Lancet 338, 1253-1255

GRIFFIN, J. F. \& MACKINTOSH, C. G. (2000) Tuberculosis in deer: perceptions, problems and progress. Veterinary Journal 160, 202-219

HARRINGTON, N. P., SURUJBALLI, O. P. \& PRESCOTT, J. F. (2006) Cervine (Cervus elaphus) cytokine mRNA quantification by real-time polymerase chain reaction. Journal of Wildlife Diseases 42,219-233

ITOH, R., KAGUBU, Y. \& ITOH F. (1992) Mycobacterium bovis infection in a herd of Japanese Sika deer (Cervus nippon). Journal of Veterinary Medical Science 54, 803-804

KAEMPFER, R. (2003) RNA sensors: novel regulators of gene expression. EMBO Reports 4, 1043-1047

KIM, J. H., SOHN, H. J., KANG, K. I., KIM, W. I., AN, J. S. \& JEAN, Y. H. (2002) Mycobacterium bovis infection in a farmed elk in Korea. Journal of Veterinary Science 3, 163-166

KOCK, M. D., JESSUP, D. A., CLARK, R. K. \& FRANTI, C. E. (1987) Effects of capture on biological parameters in free-ranging bighorn sheep (Ovis canadensis): evaluation of drop-net, drive-net, chemical immobilization and the net gun. Journal of Wildlife Diseases 23, 641-651

KOSUGE, T. \& TOYOSHIMA, S. (2000) Increased degradation of newly synthesized interferon-gamma (IFN-gamma) in anti CD3-stimulated lymphocytes treated with glycoprotein processing inhibitors. Biological and Pharmaceutical Bulletin 23, 545-548

MASSENGILL, C. E. (2004) Report of the committee on tuberculosis, Proceedings of the United States Animal Health Association Annual Meeting, Greensboro, NC, 2004. pp 581-616

MASSENGILL, C. E. (2005) Report of the committee on tuberculosis, Proceedings of the United States Animal Health Association Annual Meeting, Hershey, PA, 2004. pp 679-718

O'BRIEN, D. J., SCHMITT, S. M., FITZGERALD, S. D., BERRY, D. E. \& HICKLING, G. J. (2006) Managing the wildlife reservoir of Mycobacterium bovis: the Michigan, USA, experience. Veterinary Microbiology 112, 313-323

PALMER, M. V., WATERS, W. R. WHIPPLE, D. L., SLAUGHTER, R. E. \& JONES, S. L. (2004) Analysis of interferon- $\gamma$ production by Mycobacterium bovis-infected white-tailed deer (Odocoileus virginianus) using an in-vitro based assay. Journal of Veterinary Diagnostic Investigation 16, 16-21

PALMER, M. V., WATERS, W. R., THACKER, T. C. \& THOMSEN, B. V. (2006) Experimentally induced infection of reindeer (Rangifer tarandus) with Mycobacterium bovis. Journal of Veterinary Diagnostic Investigation 18, 52-60

PALMER, M. V., WHIPPLE, D. L. \& WATERS, W. R. (2001) Tuberculin skin testing in white-tailed deer. Journal of Veterinary Diagnostic Investigation 13, 530-533

PARRA, A., GARCIA, A., INGLIS, N. F., TATO, A., ALONSO, J. M., HERMOSO DE MENDOZA, M., HERMOSO DE MENDOZA, J. \& LARRASA, J. (2006) An epidemiological evaluation of Mycobacterium bovis infections in wild game animals of the Spanish Mediterranean ecosystem. Research in Veterinary Science 80, 140-146

QUIGLEY, F. C., COSTELLO, E., FLYNN, O., GOGARTY, A., MCGUIRK, J., MURPHY, A. \& EGAN, J. (1997) Isolation of mycobacteria from lymph node lesions in deer. Veterinary Record 141, 516-518

REHBINDER, C., EDQVIST, L-E., LUNDSTRÖM, K. \& VILLAFANE, F. (1982) A field study of management stress in reindeer (Rangifer tarandus). Rangifer $2,2-21$

SHILANG, Z. \& SHANZHI, W. U. (1985) Prevention of tuberculosis in sika deer (Cervus nippon). In Biology of Deer Production. Eds P. F. Fennessy, K. R. Drew. Bulletin in 22. Wellington, The Royal Society of New Zealand. p 154 SLOBBE, L., LOCKHART, E., KELLY, J. \& BUCHAN, G. (2000) The production and biological assessment of cervine interferon gamma. Cytokine 12, 1211-1217

SWEENEY, S. J., EMERSON, C. \& ERIKS, I. S. (2001) Cloning, sequencing, and expression of interferon-gamma from elk in North America. Journal of Wildife Diseases 37, 164-171

THACKER, T. C., PALMER, M. V. \& WATERS, W. R. (2006) Correlation of cytokine gene expression with pathology in white-tailed deer (Odocoileus virginianus) infected with Mycobacterium bovis. Clinical and Vaccine Immunology 13, 640-647

WATERS, W. R., PALMER, M. V., SLAUGHTER, R. E., JONES, S. L., PITZER, J. E. \& MINION, F. C. (2006) Diagnostic implications of antigen-induced 
gamma interferon production by blood leukocytes from Mycobacterium bovis-infected reindeer (Rangifer tarandus). Clinical and Vaccine Immunology 13, 37-44

WATERS, W. R., PALMER, M. V., WHIPPLE, D. L., SLAUGHTER, R. E. \& JONES, S. L. (2004) Immune responses of white-tailed deer (Odocoileus virginianus) to Mycobacterium bovis BCG vaccination. Journal of Wildlife Diseases 40, 66-78

WATERS, W. R., SACCO, R. E., FACH, S. J., PALMER, M. V., OLSEN, S. C. \& KREEGER, T. J. (2002) Analysis of mitogen-stimulated lymphocyte subset proliferation and nitric oxide production by peripheral blood mononuclear cells of captive elk (Cervus elaphus). Journal of Wildlife Diseases 38, 323330

WHITING, T. L. \& TESSARO, S. V. (1994) An abattoir study of tuberculosis in a herd of farmed elk. Canadian Veterinary Journal 35, 497-501

WILKINS, M. J., BARTLETT, P. C., FRAWLEY, B., O'BRIEN, D. J., MILLER, C. E. \& BOULTON, M. L. (2003) Mycobacterium bovis (bovine TB) exposure as a recreational risk for hunters: results of a Michigan Hunter Survey. International Journal of Tuberculosis and Lung Disease 10, 1001-1009 